\title{
Research on College Student Interpersonal Conflict Management based on the Conflict Theory
}

\author{
Zhonghua LI, Weifeng SHAN \\ Dep. of Disaster Information Engineering, Institute of Disaster Prevention, Sanhe, Hebei, \\ China \\ \{lizhonghua,shanweifeng\}@cidp.edu.cn
}

\begin{abstract}
:
The main connotation of interpersonal conflict management theory is introduced. Aiming to solve the main interpersonal conflict problems existing in college student, this article makes an important aspect of the research of the characters of student interpersonal conflict and the role of student interpersonal conflict, and proposes four methods to deal with the interpersonal conflict problems based on the conflict theory in order to promote the management ability of college.
\end{abstract}

Keywords: interpersonal conflict; college students; management

\section{Introduction}

The term conflict has been employed in different ways reflecting the different levels at which various conflicts exist. Within the conflict domain, considerable effort has been expended to examine the management and resolution of conflicts, identifying a number of conflict management styles interpersonal conflict management refers to the role of expectations to behavioral problems, the issue of communication between the object and role expectations, it can be generalized as two kinds of conflict: The incompatible interests on some of the substantive issues, and the negative emotions and the incompatible behavior, such as distrust, fear, denial and anger.

Within the conflict domain, considerable effort has been expended to examine the management and resolution of conflicts, identifying a number of conflict management styles interpersonal conflict management refers to the role of expectations to behavioral problems, the issue of communication between the object and role expectations, it can be generalized as two kinds of conflict: The incompatible interests on some of the substantive issues, and the negative emotions and the incompatible behavior, such as distrust, fear, denial and anger.

Interpersonal conflict management methods:

1) Compromise: an agreement reached in the process of mutual concessions by the parties to the conflict situation. The compromise is an integral part of the negotiations. the negotiations is a process between two or more individuals or groups having a common and mutually exclusive interests, According to Davis views about the role of compromise in the negotiations, it said: "The negotiations have become indispensable and necessary procedures in a free society. By compromising each other's interests conflict, it makes us understand each other's common interests, and this method 
is almost more effective than other methods taken so far."

2) Avoidance: a neutral or retreating tendency in the conflict, managers not only avoids the tendency to avoid conflict, and often play communication roles both sides of the conflict.

3) Smooth: it is the weakening of the differences of the parties to the conflict as much as possible in the case of a conflict. It emphasizes the common interests of both sides. The main purpose of taking this approach is to reduce the level of tension of the conflict.

4) Forcing: the method of forcing refers to use the power of rewards and punishments to dominate others, forcing other to comply with the decision of managers. Under normal circumstances, forcing only makes the one party of the conflict satisfied. Often in this way to resolve conflict is an incompetent performance.

5) Cooperation: both the parties to the conflict are willing to understand commonly the reason of the underlying causes of the conflict, to share information between the two sides and to jointly seek a solution beneficial to both sides. All above can make the relevant publicly face to the conflict and understand the conflict management.

\section{Characters of Students Interpersonal Conflict}

The conflict as a widespread social phenomenon, its manifestations are diverse, the root cause of the conflict is also a wide range. Researchers from a wide range of management areas agree that conflicts are an important part of organizational life and that their study is important. U.S. organizations ethnologist scientists Daft and Illinois from the book "Organizational Behavior" sum up the conflict causes from the point of view of the individual differences in the likelihood of source, in the mode, they analyze the variety of reasons of conflict by the four difference: goal difference, demand difference, value difference, and the perceived differences of goals and demand [1].

Students have more social contact with the increasing social role. They have more strengthened and more diverse purpose with people. Students' interpersonal conflicts are based on the basis of the behavior characteristics. The contemporary college students grow up under the combined effect of an ideal world, the real world and the virtual world [2]. In an ideal world, the college entrance examination-oriented education emphases the intellectual and lights moral guiding the growth of the students; the result is to ignore a child's psychological, emotional and spiritual literacy training. The real-world with wide range values, the huge negative impact has great influence on the students' the spiritual world. This influence can subvert the traditional primary and secondary education on the students enough, Therefore, the behavioral characteristics of students: They have active thinking, strong sense of self-centered, individuality, but the relative lack of norms and sense of responsibility, many students generally lack of matured psychological, some students lack deep levels of social thinking and high level ideal pursuit. The ideological and the moral level of calm is not strong mostly, there is a strong burst of the occasional emotional color on their behavior. The significant contradiction is college student behavioral characteristics of the overall activities of this behavior generally. 


\section{Roles of Students Interpersonal Conflict}

We research the resources of college student interpersonal conflict. Many scholars think that interpersonal conflicts are important factors. Studies show that interpersonal conflict closely relates to anxiety, stress, self-esteem and mental health factors; the appropriate conflict can mitigate pressure from all sides. Conflicts can make the students' life vibrant, promote students' personality and emotional development; on the other, the conflict has a negative effect, such as worsening the healthy development of students' interpersonal, hindering student life quality. We analyze the role of the Students' Interpersonal conflict from both constructive and destructive conflict.

The positive role: promoting the development of students. Firstly, it is conducive to establish a new harmonious relationship [3]. The original relationship conflict makes the conflict openly, so it is more conducive to the elimination of the negative factors, Secondly, it facilitates the ability to deal with interpersonal risk. The gap between the different students' interpersonal skills and values will promote different levels of physical conflict. In order to mitigate these conflicts, teachers or student organizers may propose an acceptable target of all, and the new goal is just to promote the healthy development of the students' interpersonal skills. Thirdly, interpersonal conflict can promote people's mental health [4].

The negative performance: If frequent and intense conflicts are not handled properly, relations between the students will continue to deteriorate. Experientially, It appears attacks unprovoked, verbal abuse, this deterioration continue for some time, groups of students will have a serious separation. The negative emotional state brings harm to the physical and mental health of students, also serious impact on the school and the community, family.

\section{Results and Analyses}

Students' interpersonal communication is an interactive process of communication between college students and other people, the exchange of ideas, emotional expression, and coordinated behavior [5]. University life is a strong stage process in Students' life. Graduating from college means the end of a relationship based on the learning, living and educational needs of the students and teachers. This reflects the students' interpersonal conflict stage. We analyze the phenomenon of college students in actual interpersonal conflict.

1) As the interpersonal conflict implements and practitioners, college students should form processing rules and awareness by compromise and cooperation with others.

It must make students aware that all conflict is not harmful. Many universities have opened mental health education programs, and these initiatives can help students' clear interpersonal conflict management theory and skills, and be able to adjust the deviant behavior of students. For example, in a dorm, students' various small contradictions in the morning till evening, are the both interrelationship between depth performances, but also provide them conditions of further enhancing the mutual feelings.

2) By the right way to deal with interpersonal conflict is college students own qualities and ability to exercise and embodied.

College students are a simple relationship, there is no conflict of interest on the substantive issues of incompatibility, in general, the most 
conflicts are negative emotions, such as not trust, fear, refused incompatible behavior and anger, the identity and behavioral characteristics of college students decide they have tendencies of "quasi-social" in interpersonal conflict, it could be given to students is a correct view of in the conflict and the positive relationship culture, for example, for low-grade students, they lack the experience of independent life and mental preparation and act, but they particularly desire friendship and love, we should give them communication, respect and trust; for high students, In comparison, they are maturity superior to lower grades. Thinking of "seeking common ground while reserving differences" is a relatively better foundation to solve college students' interpersonal conflict.

It should establish countermeasures based on the characteristics of college students' behavior management.

According to the characteristics of college students' behavior, the university teachers must establish a more feasible counter measures. Including the following:

Firstly, we must respect the point of view of the student's personality development, focus on training the student's personality, because personality is the obvious features of students' external display, respecting for the personality of the student is also the best way to cultivate the students' innovative ability, which is consistent with our traditional view.

Secondly, we should be concerned about the students 'lives, thoughts, and solve the students' interpersonal conflict management closely contact with the students' own real-life.

Thirdly, we should pay attention to the quality of students' mental of the multidisciplinary penetration education. and set more psycho-educational courses related disciplines in the university, all teachers should be also trained psycho-educational concepts, we also should penetrate psychological education and counseling throughout in teaching students in various disciplines, in order to achieve a subtle influence on the students' mental.

3) As the students interpersonal conflict mediation parties, teachers must have good communication skills and identity awareness in dealing with the conflict.

(1) Teachers as the mediation of students interpersonal conflict parties, it must recognize that he is the intermediary between the parties to the conflict, it must fully mobilize students on teacher identity recognition and trust is a premise to establish a good communication mechanism.

(2) Good communication skills mainly include the following aspects. Firstly, the two sides have established a good foundation of cognitive, Secondly, the properly use of the sense of humor or a joke to relax the tense atmosphere.

4) It must enhance students' emotional management, attention to their psychological adjustment.

In learning, work and life of the people, emotional problems are the core issue. The emotional management is a new management philosophy and management style of the management of China's higher education development in the modern stage. In order to enhance students' emotional management, it contains the following: first, it is necessary to improve the students' ability to identify emotions. We should help students to perceive their own state in the face of different emotional experience, but also to correctly identify the emotions of others, and to eliminate the emotional understanding barriers of the psychological. second, it is necessary to improve the ability of students to express emotions correctly, guide them tell their 
own emotions reasonably and properly and actively communicate with others in a reasonable, moderate to express their emotions, ultimately minimize the negative impact of venting their emotions and fight for interpersonal conflict actively. Third, it is necessary to educate students to master a good way to regulate mood. Regulation, such as sports, communication and music, etc, helps students to come out from emotional distress.

\section{Conclusions}

Conflict is an important organizational process and likely to remain so in the foreseeable future. Interpersonal conflict management can contribute to raising the level of the students ' psychological health, on the contrary, the students' psychological health is the foundation of them to correctly understand and deal with interpersonal conflict, the higher the level of mental health, and more conducive to the effective management of the college students interpersonal conflict. Consequently, researchers and teachers need to direct greater effort towards assessing the antecedents and prevention of interpersonal conflict.

The reasons for the formation of college students' interpersonal conflict is complex and diverse, both students' own reasons, such as interdependence, differences in objective and subjective reasons, also the social reasons. But regardless of what causes conflict, it requires us to analyze the nature of the conflict with a dialectical view, in order to identify the different nature of conflict a reasonable and corresponding countermeasures.

\section{Acknowledgment}

This work is supported by the Special Subject Research Project of Students Work in Institute of Disaster Prevention under grant no. XZ2012A01.

\section{References}

[1] Richard L. Daft, Raymond A. Nnoitora, Yang $\mathrm{Yu}$ and et. Organizational behavior science .M. Beijing: Mechanical Industry Press, 2004, p.236

[2] XiaoYan Zhou. J. China Education Technology, Vol. (23), 2008, p. 3-4.

[3] YiChun Zhang,Yun Wan: Organizational Behavior. BeiJing: TSinghua University Press, (2006), p.183-184.

[4] FuMin Fan, Xiang Zhang: Journal of China University of Mining and Technology, Vol.(3),2003.

[5] HanRong Wang, JianFei Long and WangXu Lang: J. Economist. Vol.(2) ,2005.

[6] Deutsch, M. "Sixty Years of Conflict," International Journal of Conflict Management, Vol. 1 (3), 1990, p. 237-263.

[7] Thomas, K.W. "Conflict and Conflict Management: Reflections and Update," Journal of Organizational Behavior, 13, 1992b, 265-274. 